\title{
Instabilidade cromossômica induzida por agroquímicos em trabalhadores rurais na região de Passo Fundo, Rio Grande do Sul, Brasil
}

\author{
Chromosome instability induced by agrochemicals \\ among farm workers in Passo Fundo, Rio Grande \\ do Sul, Brazil
}

Adil de Oliveira Pacheco 1

Christine Hackel 2

\footnotetext{
1 Laboratório de Citogenética Humana, Instituto de Ciências Biológicas, Universidade de Passo Fundo. Campus I, BR 285, Km 171, Passo Fundo, RS 90001-970, Brasil.

adil@vitoria.upf.tche.br

2 Departamento de Genética Médica, Faculdade

de Ciências Médicas, Universidade Estadual de Campinas. C. P. 6111, Campinas, SP 13081-970, Brasil. hackel@unicamp.br
}

\begin{abstract}
A major share of the grain farming (wheat and soybeans) in the State of Rio Grande do Sul is in the Passo Fundo area. For crop pest control, large amounts of agrochemicals (fungicides, insecticides, and herbicides) are used. To evaluate the genotoxicity of these products, the micronucleus test was performed in farm workers directly exposed to these chemicals. Heparinized blood samples were drawn by venipuncture from 30 exposed workers and 30 non-exposed controls. Micronuclei frequency was evaluated by counting 1,000 binucleated cells per individual in both groups. Smoking habits, age, and duration of exposure showed no effect on the frequency of micronuclei in both groups. However, statistical analysis showed significantly higher mean numbers of binucleated cells with micronuclei in exposed individuals (14.3/1,000 cells) as compared to controls (7.1/1,000 cells), allowing the authors to conclude that the micronucleus test is an efficient biological assay for monitoring population exposure to mixtures of agrochemicals.
\end{abstract}

Key words Occupational Health; Poisoning; Pesticide Exposure; Chromosome Aberrations

Resumo A região de Passo Fundo no Planalto Médio do Rio Grande do Sul, caracteriza-se pela produção de grãos (trigo, soja), nas quais grandes quantidades de agroquímicos (fungicidas, inseticidas e herbicidas) são utilizadas. Para avaliar a atividade genotóxica desses produtos em seres humanos, utilizou-se a técnica de micronúcleos, através de amostras de sangue periférico de trinta trabalhadores expostos e de trinta indivíduos controles não expostos. A freqüência de micronúcleos foi avaliada em 1.000 células binucleadas por indivíduo em ambos os grupos. Fatores como tabagismo, idade e tempo de exposição não exerceram qualquer efeito sobre a freqüência de micronúcleos em ambos os grupos. No entanto, a análise estatística revelou números significativamente mais elevados de micronúcleos em expostos (14,3/1.000 células) do que em não expostos $(7,1 / 1.000$ células), indicando que o teste do micronúcleo é um ensaio biológico eficiente para monitorar populações expostas a misturas de agroquímicos.

Palavras-chave Saúde Ocupacional; Envenenamento; Exposição a Praguicidas; Aberrações Cromossômicas 


\section{Introdução}

O crescimento industrial nos centros urbanos provocou deterioração do meio ambiente com influências na saúde da humanidade (Lopes et al., 1992). A exposição ocupacional a vários tipos de agentes cancerígenos como fertilizantes, praguicidas, fungicidas, herbicidas e outros produtos químicos (Lopes et al., 1992), têm contribuído para que esse seja um dos principais problemas de saúde pública nos países pouco desenvolvidos (Paumgartten et al., 1998).

Agentes genotóxicos são capazes de induzir instabilidade cromossômica, como por exemplo, aberrações cromossômicas não casuais, principalmente deleções, translocações e o ganho ou perda de cromossomos inteiros, contribuindo para o desenvolvimento de processos celulares malignos (Cavanee et al., 1983; Klein, 1981; Rowley, 1984; Tsutsui et al., 1983; Yunis, 1983).

Resultados conflitantes têm sido obtidos por diferentes grupos de pesquisadores em ensaios para avaliar o potencial genotóxico de uma grande variedade de pesticidas. Em trabalhadores rurais e da indústria de pesticidas, observou-se uma forte associação entre alterações cromossômicas e a exposição a produtos comercialmente conhecidos como Ziram, Zineb, Thiram, Triclorfom, Fosmet, Dazinon e Primicarb (Pàldy et al., 1987). Em relação ao efeito clastogênico, enquanto que o DDT demonstrou relação positiva na indução de quebras cromossômicas (Rabello et al., 1975), nenhum aumento apreciável foi observado em trabalhadores expostos ao Lidane (Kiràly et al., 1979). Resultados negativos na análise cromossômica também foram relatados em relação a Clorinol e Buvinol (Czeizel et al., 1976) e ainda, ao Dicloropropano (Kapp et al., 1979).

Porém, vários estudos realizados em indivíduos que mantiveram contato profissional com mistura de praguicidas em diversos países, indicaram a ocorrência de aberrações cromossômicas (Bréga et al., 1998; Crossen et al., 1978; Nehèz et al., 1981; Shabtai et al., 1979; Yoder et al., 1973).

As análises de micronúcleos em linfócitos de sangue periférico de seres humanos e em linhagens de células cultivadas, mostraram ser efetivas para medir danos citogenéticos de agentes com diferentes mecanismos de genotoxicidade (Eastmond \& Tucker, 1989; Fenech \& Morley, 1985; Norppa et al., 1993b). Várias pesquisas foram realizadas utilizando cultura de linfócitos de sangue periférico in vitro, para avaliar o efeito de diferentes praguicidas. Em experimentos com trimeltin clorídrico, Ghosh et al.
(1990) concluíram que esse biocida é um potente clastógeno. Surrallés et al. (1995) testaram cinco diferentes inseticidas piretróides e observaram atividade genotóxica para três deles. Ensaios realizados com Flucoralin em doses acima de $20,0 \mathrm{mg} / \mathrm{ml}$, induziram um aumento significativo de células micronucleadas (Panneerselvam et al., 1995).

O efeito clastogênico dos agroquímicos sobre as células somáticas humanas de indivíduos expostos foi avaliado em nosso trabalho, através da análise de micronúcleos em linfócitos de sangue periférico.

\section{Materiais e métodos}

Foram coletadas amostras de sangue periférico de trinta indivíduos envolvidos no cultivo de soja e de trigo, no Hospital São Vicente de Paulo de Passo Fundo (HSVP) e no Centro de Estudos Agropecuários (CEPAGRO) da Universidade de Passo Fundo (UPF), no período de setembro de 1998 a agosto de 1999.

No Hospital, foram coletadas amostras de vinte trabalhadores internados para a investigação de doenças hematológicas, antes da administração de qualquer medicamento. No CEPAGRO, outros dez trabalhadores, sem queixas clínicas, submeteram-se à coleta.

Todos os indivíduos forneceram informações relativas ao hábito de fumar, ingestão de bebida alcoólica e tempo de exposição a defensivos agrícolas (fungicidas, inseticidas e herbicidas) e assinaram o protocolo de Consentimento Informado.

Como grupo controle, foram obtidas amostras de trinta indivíduos não expostos, seguindo-se os mesmos procedimentos de coleta e entrevista. Desse grupo, todos eram funcionários dos setores administrativos da UPF. Todos os indivíduos estudados (expostos e não-expostos) eram de origem caucasóide.

De cada indivíduo foram coletados $2 \mathrm{ml} \mathrm{de}$ sangue periférico em seringa descartável, sendo esse material imediatamente transportado, em caixa de isopor com gelo, para o Laboratório de Citogenética Humana da UPF. Em paralelo, selecionou-se um indivíduo não exposto, da mesma idade ou dentro de uma variação de \pm 5 anos para controle.

As culturas foram realizadas de acordo com Titenko-Holland et al. (1997), por meio da adição de $0,2 \mathrm{ml}$ de sangue periférico em frasco contendo 4,5ml de meio de cultura RPMI 1640 suplementado com $15 \%$ de soro fetal bovino, $0,1 \mathrm{ml}$ de L-glutamina e $0,1 \mathrm{ml}$ de fitohemaglutinina. Após 48 horas de incubação, foram adi- 
cionados $0,2 \mathrm{ml}$ de Citocalasina B para cada $5 \mathrm{ml}$ de meio, para impedir a citocinese das células em divisão. Ao completar 72 horas, a cultura foi interrompida com $0,5 \mathrm{ml}$ de fixador metanolácido acético (3:1) durante 5 minutos à temperatura ambiente. $\mathrm{O}$ material foi submetido à centrifugação a 800rpm, descartando-se o sobrenadante. A seguir, adicionou-se $5 \mathrm{ml}$ de fixador, agitando-se o material e realizando-se nova centrifugação. Esse procedimento foi repetido 3 a 4 vezes, até o precipitado ficar limpo. O material foi gotejado sobre lâminas que foram secas à temperatura ambiente e coradas com Giemsa (Wright) na proporção de 1:3 em tampão fosfato ( $\mathrm{pH}=6,8$ ) durante 5 a 8 minutos.

As lâminas foram examinadas em teste-cego. Para cada indivíduo foram contados mil linfócitos binucleados, identificando-se os micronúcleos de acordo com os critérios propostos por Titenko-Holland et al. (1997). Os dados foram analisados estatisticamente, utilizandose o teste $t$ com o nível de significância de $5 \%$. Foi também utilizado o teste de regressão linear com o auxilio do programa BioEstat (Ayres \& Ayres Jr., 1998), para confirmar os resultados obtidos com o teste $t$.

Os dados utilizados no presente trabalho cumprem os princípios éticos da Declaração de Helsinki (1996). Para tanto, todos os envolvidos preencheram e assinaram o Consentimento Informado ficando uma via com o pesquisador e outra para o doador voluntário.

\section{Resultados}

Os resultados obtidos a partir da contagem de mil células binucleadas dos indivíduos do grupo exposto, são apresentados na Tabela 1 e os referentes aos indivíduos do grupo controle estão listados na Tabela 2.

Nos trabalhadores expostos a média de idade foi 41,8 anos enquanto que no grupo controle a média foi de 40,4 anos. O tempo médio de exposição aos praguicidas foi de 10,7 anos. Entre os fumantes, somente o indivíduo identificado pelo número 13 (Tabela 1), relatou ter fumado por mais de 35 anos, os demais referiram uma exposição menor a esse componente e haviam deixado o hábito há mais de três anos.

Uma vez que as amostras dos trabalhadores expostos foram coletadas em dois locais diferentes (HSPV e CEPAGRO), os dados referentes à análise de micronúcleos (MN) dos vinte indivíduos internados, foram comparados com os obtidos nos dez indivíduos expostos, sem sintomatologia clínica. Não foram detectadas diferenças estatisticamente significativas entre eles $\left(t_{\text {calc }}=1,3682\right.$; G.L. $\left.=28, \mathrm{p}=0,1821\right)$, de forma que esses dados foram agrupados para as análises subseqüentemente realizadas.

O número médio de células $\mathrm{MN}$ encontrado no grupo dos trabalhadores expostos foi de 14,3, e 7,1 no grupo dos doadores não-expostos, sendo essa diferença estatisticamente significativa $\left(t_{\text {calc }}=4,2855 ;\right.$ G.L. $\left.=58, \mathrm{p}<0,0001\right)$.

A comparação entre não-fumantes expostos ( $\mathrm{n}=22 ; 13,91 \mathrm{MN} / 1.000$ células) e não-fumantes controles $(\mathrm{n}=26 ; 7,15 \mathrm{MN} / 1.000$ células) revelou a existência de um aumento estatisticamente significativo do número de células $\mathrm{MN}$ no primeiro grupo $\left(t_{\text {calc }}=3,5842 ;\right.$ G.L. $=46 ; \mathrm{p}=0,0008$ ). Já entre fumantes expostos $(\mathrm{n}=8 ; 15,25 \mathrm{MN} /$ 1.000 células) e fumantes não-expostos $(n=4$; $6,50 \mathrm{MN} / 1.000$ células) não houve diferença estatisticamente significativa ao nível de $5 \%\left(t_{\text {calc }}=\right.$ 2,0278; G.L. = 10; $\mathrm{p}=0,0701$ ), provavelmente devido ao pequeno número de indivíduos em cada categoria.

A análise de regressão linear permitiu confirmar esses achados, em relação à idade e ao tempo de exposição. Nos indivíduos expostos, não houve influência da idade $(\mathrm{F}=0,0311 ; \mathrm{p}=$ 0,8554; $\mathrm{r}=-0,0195)$ ou dos anos de exposição ( $\mathrm{F}=$ $0,5510 ; \mathrm{p}=0,5295 ; \mathrm{r}=0,1124)$ sobre o número de células binucleadas com micronúcleos. A variável idade também não exerceu influência sobre a expressão de micronúcleos no grupo de doadores não-expostos ( $\mathrm{F}=1,9460 ; \mathrm{p}=0,1709$; $r=0,1144$ ).

Também foram avaliados os dados relativos ao tempo de exposição, idade e tabagismo em cada grupo. Os resultados dessa análise estatística demonstraram não ocorrer diferenças significativas. A influência das variáveis sexo e ingestão de álcool não pôde ser estatisticamente avaliada, tendo em vista o pequeno número indivíduos de sexo feminino e a presença de apenas um indivíduo no grupo controle com relato de consumo freqüente de bebidas alcoólicas.

\section{Discussão}

A utilização de agroquímicos para controlar as pragas da lavoura é um fato inegável, porém os cuidados com seu manuseio continuam sendo negligenciados pelos aplicadores e pelo poder público que regulamenta o seu uso. Vários relatos apontam para a má utilização desses produtos pelo homem (Paumgartten et al., 1998).

Os resultados obtidos comparando trinta indivíduos expostos a essas substâncias químicas utilizadas nas plantações de Passo Fundo, Rio Grande do Sul, demonstram que as altera- 
Tabela 1

Dados referentes ao número de células binucleadas com micronúcleos (MN), hábito de fumar, ingestão de álcool, idade, sexo e tempo de exposição a agroquímicos de trabalhadores expostos.

\begin{tabular}{|c|c|c|c|c|c|c|}
\hline Indivíduo* & $\begin{array}{l}\text { MN/1.000 linfócitos } \\
\text { binucleados }\end{array}$ & Fumo** & Álcool** & $\begin{array}{l}\text { Idade } \\
\text { (anos) }\end{array}$ & $\begin{array}{l}\text { Tempo de } \\
\text { exposição (anos) }\end{array}$ & Sexo \\
\hline 01 & 17 & - & - & 29 & 4 & Masculino \\
\hline 02 & 20 & - & - & 39 & 10 & Masculino \\
\hline 03 & 16 & - & - & 30 & 5 & Masculino \\
\hline 04 & 14 & - & - & 25 & 7 & Masculino \\
\hline 05 & 11 & - & - & 27 & 5 & Masculino \\
\hline 06 & 6 & + & - & 47 & 4 & Masculino \\
\hline 07 & 16 & - & - & 40 & 10 & Masculino \\
\hline 08 & 19 & - & - & 44 & 12 & Masculino \\
\hline 09 & 27 & - & - & 39 & 20 & Masculino \\
\hline 10 & 23 & + & - & 37 & 10 & Masculino \\
\hline 11 & 7 & - & - & 29 & 15 & Masculino \\
\hline 12 & 15 & - & - & 24 & 5 & Feminino \\
\hline 13 & 24 & + & - & 54 & 45 & Masculino \\
\hline 14 & 14 & - & - & 70 & 2 & Feminino \\
\hline 15 & 20 & + & - & 47 & 7 & Masculino \\
\hline 16 & 6 & + & - & 66 & 2 & Masculino \\
\hline 17 & 5 & - & - & 50 & 2 & Masculino \\
\hline 18 & 8 & + & - & 52 & 3 & Masculino \\
\hline 19 & 2 & - & - & 33 & 15 & Masculino \\
\hline 20 & 11 & + & - & 58 & 10 & Masculino \\
\hline 21 & 4 & - & - & 50 & 30 & Masculino \\
\hline 22 & 9 & - & - & 37 & 10 & Masculino \\
\hline 23 & 3 & - & - & 43 & 25 & Masculino \\
\hline 24 & 19 & - & - & 33 & 8 & Masculino \\
\hline 25 & 19 & - & - & 39 & 8 & Masculino \\
\hline 26 & 12 & - & - & 24 & 11 & Masculino \\
\hline 27 & 28 & - & - & 67 & 15 & Masculino \\
\hline 28 & 24 & + & - & 45 & 3 & Feminino \\
\hline 29 & 23 & - & - & 27 & 15 & Masculino \\
\hline 30 & 6 & - & - & 49 & 4 & Masculino \\
\hline
\end{tabular}

* Amostras 1 a 10 coletadas no Centro de Estudos Agropecuários, Universidade de Passo Fundo; amostras 11 a 30 coletadas no Hospital São Vicente de Paulo.

** (-) não fumante e não ingere álcool; (+) fumante e ingere álcool.

ções cromossômicas, sob a forma de micronúcleos (Figura 1), estão presentes em uma freqüência bem mais elevada do que em 30 indivíduos não expostos, da mesma região.

Esses dados estão de acordo com a maioria dos estudos cromossômicos realizados em trabalhadores expostos a misturas de pesticidas, independentemente do parâmetro citogenético avaliado. Assim, aumentos significativos na incidência de aberrações cromossômicas e/ou no intercâmbio de cromátides irmãs, foram constatadas por De Ferrari et al. (1991), em floricultores; por Kourakis et al. (1992), em trabalhadores em casas de vegetação e por Carbonell et al. (1995) e Bréga et al. (1998), em trabalha- dores de zonas rurais. Em relação aos micronúcleos, sua freqüência acha-se significativamente aumentada nos floricultores italianos estudados por Bolognesi et al. (1993), embora Scarpato et al. (1996) relatem achados negativos em estudo semelhante.

Com relação a variáveis como hábito de fumar, idade e tempo de exposição, o teste estatístico não apontou diferenças significativas em relação à freqüência de células com micronúcleos entre os expostos e não-expostos da região de Passo Fundo. Como visto, a influência das variáveis sexo e ingestão de álcool não pôde ser avaliada no presente trabalho, devido a presença de apenas três indivíduos de sexo fe- 
minino em cada grupo e a de apenas um indivíduo no grupo controle com relato de consumo freqüente de bebidas alcoólicas.

Em relação ao hábito de fumar, os presentes achados estão de acordo com aqueles encontrados por Kourakis et al. (1992), que estudaram a freqüência de aberrações cromossômicas em linfócitos de 29 trabalhadores expostos a uma mistura de pesticidas, e não encontraram diferenças significativas entre fumantes e não fumantes. De modo semelhante, Barale et al. (1998) analisaram materiais obtidos em culturas de linfócitos de 1.650 indivíduos italianos, e não encontraram relação entre o hábito de fumar e o aumento na freqüência de micronúcleos.

Conclusões similares foram obtidas por outros pesquisadores que não constataram nenhum efeito do hábito de fumar com relação à freqüência de MN (Bolognesi et al., 1993; Bonassi et al., 1994; Norppa et al., 1993a; Pitarque et al., 1996; Stierum et al., 1993; Thierens et al., 1996; van Hummelen et al., 1993). Apenas Da Cruz et al. (1994) relatam uma associação significante entre $\mathrm{MN}$, hábito de fumar e ingestão de bebida alcoólica, em indivíduos expostos.

Os dados obtidos no presente trabalho, revelam que o efeito da exposição a misturas de pesticidas praticamente não é influenciado pelo tabagismo, pois, mesmo a comparação entre não-tabagistas expostos e não-expostos revela a existência de um aumento altamente significativo da freqüência de células com micronúcleos no grupo exposto ( $\mathrm{p}=0,0008$ ).

Dentre outras variáveis que podem influir na expressão de micronúcleos, a idade tem sido constantemente avaliada. Considera-se que o aumento na freqüência de micronúcleos em relação à idade pode ser decorrente do aumento de fragmentos acêntricos, causado por quebras no DNA induzidas endogenamente ou por exposição a clastógenos ambientais, ou por um aumento no número de distúrbios do fuso, resultando em atraso cromossômico na anáfase (Thierens et al., 1996).

Uma análise realizada por um grupo nórdico de pesquisadores (Nordic Study Group on the Health Risk of Chromosome Damage, 1990), sobre danos cromossômicos somáticos em mais de 3 mil indivíduos, concluíram que as mulheres apresentaram níveis mais elevados de aberrações cromossômicas, de intercâmbios de cromátides irmãs e de micronúcleos do que os homens. Esses achados estão de acordo com os observados por vários autores (Bender et al., 1988; Galloway et al., 1986; Hedner et al., 1982; Margolin \& Shelby, 1985), enquanto que outros autores não encontraram nenhum efeito com relação ao sexo (Anderson et al., 1991).

\begin{tabular}{|c|c|c|c|c|c|}
\hline \multicolumn{6}{|c|}{$\begin{array}{l}\text { Dados referentes ao número de células binucleadas com micronúcleos (MN), } \\
\text { hábito de fumar, ingestão de álcool, idade e sexo dos doadores voluntários } \\
\text { do grupo controle. }\end{array}$} \\
\hline Doador & $\begin{array}{l}\text { MN/1.000 linfócitos } \\
\text { binucleados }\end{array}$ & Fumo* & Álcool* & $\begin{array}{l}\text { Idade } \\
\text { (anos) }\end{array}$ & Sexo \\
\hline 01 & 8 & - & + & 30 & Masculino \\
\hline 02 & 10 & - & - & 38 & Masculino \\
\hline 03 & 4 & - & - & 33 & Masculino \\
\hline 04 & 2 & - & - & 25 & Masculino \\
\hline 05 & 1 & - & - & 27 & Masculino \\
\hline 06 & 7 & - & - & 46 & Masculino \\
\hline 07 & 5 & - & - & 40 & Masculino \\
\hline 08 & 6 & + & - & 43 & Masculino \\
\hline 09 & 11 & - & - & 38 & Masculino \\
\hline 10 & 2 & - & - & 34 & Masculino \\
\hline 11 & 3 & - & - & 28 & Masculino \\
\hline 12 & 12 & - & - & 23 & Feminino \\
\hline 13 & 10 & + & - & 50 & Masculino \\
\hline 14 & 15 & - & - & 62 & Feminino \\
\hline 15 & 7 & - & - & 40 & Masculino \\
\hline 16 & 3 & - & - & 63 & Masculino \\
\hline 17 & 2 & - & - & 50 & Masculino \\
\hline 18 & 3 & - & - & 53 & Masculino \\
\hline 19 & 13 & - & - & 33 & Masculino \\
\hline 20 & 6 & - & - & 58 & Masculino \\
\hline 21 & 6 & + & - & 52 & Masculino \\
\hline 22 & 1 & - & - & 38 & Masculino \\
\hline 23 & 18 & - & - & 38 & Masculino \\
\hline 24 & 4 & + & - & 29 & Masculino \\
\hline 25 & 2 & - & - & 39 & Masculino \\
\hline 26 & 8 & - & - & 24 & Masculino \\
\hline 27 & 19 & - & - & 62 & Masculino \\
\hline 28 & 17 & - & - & 46 & Feminino \\
\hline 29 & 3 & - & - & 26 & Masculino \\
\hline 30 & 4 & - & - & 44 & Masculino \\
\hline
\end{tabular}

* (-) não fumante e não ingere álcool; (+) fumante e ingere álcool.

No presente trabalho, apenas três indivíduos do sexo feminino foram avaliados em cada grupo, pertencentes a três faixas etárias diferentes (< 25 anos; 40-45 anos; > 60 anos). Uma vez que expostos e controles foram emparelhados por sexo e idade, se de fato ocorreu algum efeito dessas variáveis sobre a análise de micronúcleos em nossa amostra, deve ter acontecido em ambos os grupos de modo semelhante.

Analisados isoladamente, os resultados relativos ao sexo, os indivíduos de idade mais avançada do sexo feminino, tanto no controle quanto nos expostos, apresentaram uma freqüência mais alta de micronúcleos. Esses resultados es- 
Figura 1

Linfócitos binucleados corados com Giemsa-Wright. Notar em ambas as imagens (a-b), a presença de micronúcleos (MN)
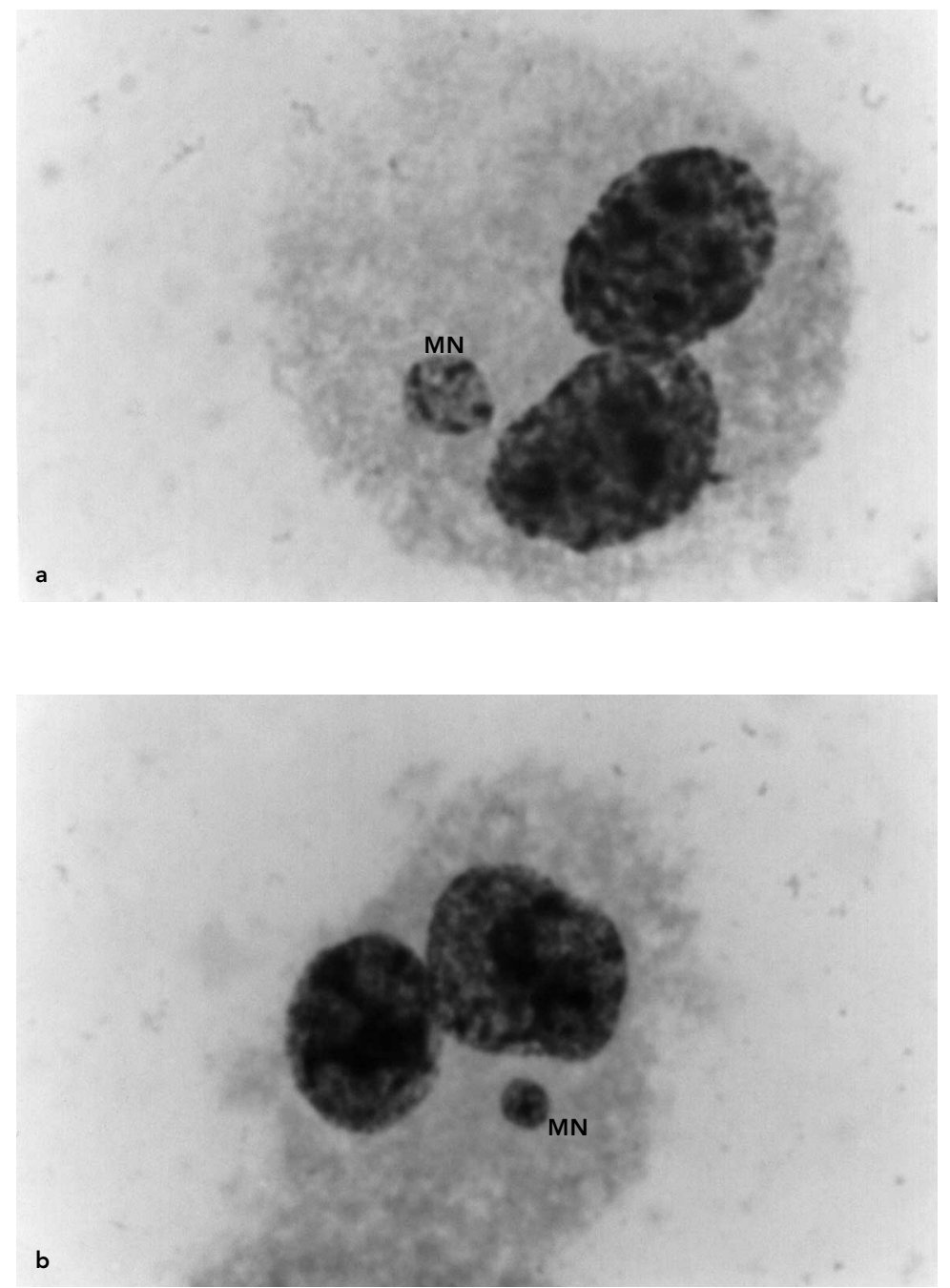

Aumento: $1200 X$ idade do que no grupo controle. Entretanto, não parece claro se a aparente diminuição das taxas de quebras cromossômicas em indivíduos com mais de 15 anos de exposição, reflete um fenômeno mais eficiente de eliminação de células anômalas ou se apenas os indivíduos mais hígidos persistiriam por mais anos no mesmo ambiente de trabalho.

Nossos dados não permitem esclarecer essa questão, uma vez que o tempo de exposição não exerceu influência significativa sobre a freqüência de micronúcleos. Cabe mencionar, que o tempo médio de exposição dos trabalhadores rurais expostos da região de Passo Fundo aqui estudados foi de 10,7 anos, situando-se muito próximo da faixa crítica delineada por Páldy et al. (1987). Com efeito, dentre os trinta trabalhadores examinados, 15 apresentavam tempo de exposição inferior a 10 anos, 11 situavam-se entre 10 e 15 e apenas quatro estavam expostos há mais de 15 anos. Os valores médios de células com micronúcleos para cada um desses três grupos foram: 13; 15,5 e 14,5, respectivamente.

Carbonell et al. (1995) observaram uma redução na quantidade de aberrações cromossômicas em seus estudos com um grupo de agricultores, durante o período de baixa exposição, o que está de acordo com os achados de outros investigadores (van Bao et al., 1974), os quais relataram que em pacientes sofrendo de intoxicação aguda por inseticida organofosforado, a alta taxa de quebras cromatídicas foi reduzida a valores do controle em aproximadamente seis meses. Essa redução pode ser atribuída ao fato de que aqueles linfócitos carregando aberrações cromossômicas tenham sido eliminados da corrente circulatória.

Entretanto, os trabalhadores rurais da Região de Passo Fundo sofrem um processo de exposição contínua, já que as culturas se sucedem com pequenos intervalos entre uma e outra. Como se sabe, a cultura de trigo é característica do inverno e a de soja, do verão, a colheita de uma implica no plantio da outra.

Medidas de proteção devem ser intensificadas na tentativa de orientar os trabalhadores rurais responsáveis pelo manuseio e aplicação dos praguicidas. Os resultados obtidos em pesquisas, que utilizam material proveniente desses profissionais, servem como uma forma de esclarecer sobre os riscos e melhorar a qualidade de vida do trabalhador rural.

\section{Conclusões}

A partir dos dados obtidos pela análise das culturas de linfócitos periféricos de trinta traba- 
lhadores rurais expostos a agroquímicos da região de Passo Fundo, comparados com trinta indivíduos não expostos, pode-se concluir que houve um aumento significativo na freqüência de micronúcleos nos indivíduos expostos. As variáveis hábito de fumar, idade e tempo de exposição, não influenciaram de modo significativo a ocorrência de micronúcleos, tanto nos indivíduos expostos quanto nos controles, e o teste do micronúcleo demonstrou ser um ensaio biológico eficiente para o monitoramento da exposição a misturas de pesticidas nessa população.

\section{Referências}

ANDERSON, D.; FRANCIS, A. J.; GODBERT, P.; JENKINSON, P. C. \& BUTTERWORTH, K. R., 1991. Chromosome aberrations (CA), sister chromatid exchanges (SCE) and mitogen-induced blastogenesis in cultured peripheral lymphocytes from 48 control individuals sampled 8 times over 2 years. Mutation Research, 250:467-476.

AYRES, M. \& AYRES Jr., M. A., 1998. BioEstat: Aplicações Estatísticas nas Áreas das Ciências Biológicas e Médicas. Manaus: Sociedade Civil Mamirauá/ Conselho Nacional de Desenvolvimento Científico e Tecnológico.

BARALE, R.; CHELOTTI, L.; DAVIVI, T.; DEL RY, S.; ANDREASSI, M. G.; BALLARDIN, M.; BULLERI, M.; HE, J.; BALDACCI, S.; DI PEDE, F.; GEMIGNANI, F. \& LANDI, S., 1998. Sister chromatid exchange and micronucleus frequency in human lymphocytes of 1650 subjects in an Italian population: II. Contribution of Sex, age, and lifestyle. Environmental and Molecular Mutagenesis, 31: 228-242.

BENDER, M. A.; PRESTON, R. J.; LEONARD, R. C.; PYATT, B. E.; GOOCH, P. C. \& SHELBY, M. S., 1988. Chromosomal aberration and sister-chromatid frequencies in peripheral lymphocytes of a large human population sample. Mutation Research, 204:421-433.

BOLOGNESI, C.; PARRINI, N.; BONASSI, S.; IANELLO, G. \& SALANITO, A., 1993. Cytogenetic analysis of a human population occupationally exposed to pesticides. Mutation Research, 285:239-249.

BONASSI, S.; CEPPI, M.; FONTANA, V. \& MERLO, F., 1994. Multiple regression analysis of cytogenetic human data. Mutation Research, 323:69-84.
BRÉGA, S. M.; VASSILIEFF, I.; ALMEIDA, A.; MERCADANTE, A.; BISSACOT, D.; CURY, P. R. \& FREIRE-MAIA, D. V., 1998. Clinical, cytogenetic and toxicological studies in rural workers exposed to pesticides in Botucatu, São Paulo, Brazil. Cadernos de Saúde Pública, 14(Sup. 3):109-115.

CARBONELL, E.; VALBUENA, A.; XAMENA, N.; CREUS, A. \& MARCOS, R., 1995. Temporary variations in chromosomal aberrations in a group of agricultural workers exposed to pesticides. Mutation Research, 344:127-134.

CATALAN, J.; AUTIO, K.; WESSMAN, M.; LINDHOLM, C.; KNUUTILA, S.; SORSA, M. \& NORPPA, H., 1995. Age-associated micronuclei containing centromeres ans the $\mathrm{X}$ chromosome in lymphocytes of human. Cytogenetics and Cell Genetics, 68:11-16.

CAVANEE, W. K.; DRYJA, T. P.; PHILLIPS, R. A.; BENEDICT, W. F.; GOBOUT, R.; GALLIC, B. L.; MURPHEE, A. L.; STRONG, L. C. \&WHITE, R. L., 1983. Expression of recessive alleles by chromosomal mechanisms in retinoblastoma. Nature, 305:779-784.

CROSSEN, P. E.; MORGAN, W. P. \& HORAN, J. J., 1978. Cytogenetic studies of pesticide and herbicide sprayers. New Zealand Medicine, 88:192-195.

CZEIZEL, E.; KIRALY, J. \& RUZICSKA, P., 1976. Proceedings: Studies on chromosomal mutations in workers producing organophosphate insecticides. $\mathrm{Mu}$ tation Research, 29:279.

DA CRUZ, A. D.; McARTHUR, A. G.; SILVA, C. C.; CURADO, M. P. \& GLICKMAN, B. W., 1994. Human micronucleus counts are correlated with age, smoking, and cesium-137 dose in the Goiânia (Brazil) radiological accident. Mutation Research, 313:57-68. 
DE FERRARI, M.; ARTUSO, M.; BONASSIN, S.; BONATI, S.; CAVALIERRI, Z.; PESCATORE, F.; MARCHINI, E.; PISANO, V. \& ABBONDANDOLO, A., 1991. Cytogenetic biomonitoring of an Italian population exposed to pesticides: Chromosome aberration and sister-chromatid exchange analysis in peripheral blood lymphocytes. Mutation Research, 260:105-113.

EASTMOND, D. A. \& TUCKER, J. D., 1989. Identification of aneuploidy-inducing agents using cytokinesisblocked human lymphocytes and an antikinetochore antibody. Environmental and Molecular Mutagenesis, 13:34-43.

FENECH, M. \& MORLEY, A. A., 1985. Measurement of micronuclei in lymphocytes. Mutation Research, 147:29-36

GALLOWAY, S. M.; BEERY, P. K.; NICHOLS, W. W.; WOLMAN, S. R.; SOPER, K. A.; STOLLEY, P. D. \& ARCHER, P., 1986. Chromosome aberrations in individuals occupacionally exposed to ethilene oxide, and in a large control population. Mutation Research, 170:55-74.

GHOSH, B. B.; TALUKDER, G. \& SHARMA, A., 1990. Frequency of micronuclei induced in peripheral lymphocytes by trimelthyltin chloride. Mutation Research, 245:33-39.

HEDNER, K.; HÖGSTEDT, B.; KOLNIG, A. M.; MARKVENDEL, E.; STRÖMBECK, B. \& MITELMAN, F., 1982. Sister chromatid exchanges and structural chromosome aberrations in relation to age and sex. Human Genetics, 62:305-309.

KAPP, R. W.; PICCIANO, D. J. \& JACOBSON, C. B., 1979. YChromosomal nondisjunction in dibromochloropropane exposed workmen. Mutation Research, 64:47-51.

KIRÀLY, J.; SZENTEZI, I.; RUZICSKA, M. \& CZEIZEL, A., 1979. Chromosome studies in workers producing organophosphate insecticides. Archives of Environmental Contamination and Toxicology, 8:309-319.

KLEIN, G., 1981. The role of gene dosage and genetic transposition in carcinogenesis. Nature, 294:313316.

KOURAKIS, A.; MOURATIDOU, M.; KOKKINOS, G.; BARBOUTI, A.; KOTSIS, A.; MOURELATOS, D. \& DOZI-VASSILIADES, J., 1992. Frequencies of chromosomal aberrations in pesticide sprayers working in plastic green houses. Mutation Research, 279:145-148.

LOPES, E. R.; MENDONÇA, G. A. S.; GOLDFARB, L. M. C. S.; AGUINAGA, S.; COSTA-E-SILVA, V. L.; MATTOS, I. E.; CURADO, M. P.; SAKAMOTO, L. H.; FONSECA, L. A. M.; TABAK, D. E.; SIQUEIRA, M. S. N.; RUMJANEK, V. M.; ROSEMBERG, J.; DE MORAES, M. S. A.; BORGES, N. F.; CARDOSO, V. M. \& ETGES, V. E., 1992. Câncer e meio ambiente. Revista Brasileira de Cancerologia, 38:35-64.

MARGOLIN, B. H. \& SHELBY, M. D., 1985. Sister chromatid exchanges: A reexamination of the evidence for sex and race differences in humans. Environmental Mutagenesis, 7(Sup. 4):63-72.

NEHĖZ, M.; BERENCZI, G.; PÁLDY, A.; SELYPES, A.; CZEIZEL, E.; SZENTESI, I.; CZANKÓ, J.; LÉVAY, K.; MAURER, J. \& NAGY, E., 1981. Data on the chromosome examinations of workers exposed to pesticides. Regulatory Toxicology and Pharmacology, 1:116-122.
NORDIC STUDY GROUP ON THE HEALTH RISK OF CHROMOSOME DAMAGE, 1990. A Nordic data base on somatic chromosome damage in humans. Mutation Research, 241:325-337.

NORPPA, H.; LUOMAHAARA, S.; HEIKANEN, H.; ROTH, S.; SORSA, M.; RENZI, L. \& LINDHOLM, C., 1993a. Micronucleus assay in lymphocytes as a tool to biomonitor human exposure to aneuploidogens and clastogens. Environmental Health Perspectives, 101(Sup. 3):139-143.

NORPPA, H.; RENZI, L. \& LINDHOLM, C., 1993b. Detection of whole chromosomes in micronuclei of citokinesis-blocked human lymphocytes by antikinetochore staining and in situ hybridization. Mutagenesis, 8:519-225.

PÀLDY, A.; PUSKÁS, N.; VINECZE, K. \& HADHÁZI, M., 1987. Cytogenetic studies on rural populations exposed to pesticides. Mutation Research, 187:127132.

PANNEERSELVAM, N.; SINHA, S. \& SHANMUGAM, G., 1995. Genotoxicity of the herbicide fluchloralinon human lymphocytes "in vitro": Chromosomal aberration and micronucleus tests. Mutation Research, 344:69-72.

PAUMGARTTEN, F. J. R.; DELGADO, F. I.; OLIVEIRA, E. S.; ALLELUIA, I. B.; BARRETO, H. H. C. \& KUSSUMI, T. A., 1998. Levels of organochlorine pesticides in the blood serum of agricultural workers from Rio de Janeiro state, Brazil. Cadernos de Saúde Pública, 14(Sup. 3):33-39.

PITARQUE, M.; CARBONELL, E.; LAPENA, N.; MARSA, M.; TORRES, M.; CREUS, A.; XAMENA, N. \& MARCOS, R., 1996. No increase in micronuclei frequency in cultured blood lymphocytes from a group of filling station attendants. Mutation Research, 367:161-167.

RABELLO, M. M.; DE ALMEIDA, W. F. \& PIGATI, P., 1975. Cytogenetic study on individuals occupationally exposed to DDT. Mutation Research, 28: 339-354.

ROWLEY, J. D., 1984. Biological implications of consistent chromosome rearrangements in leukemia and lymphoma. Cancer Research, 44:3159-3161.

SCARPATO, R.; MIGLIORE, L.; ANGOTZI, G.; FEDI, A.; MILIGI, L. \& LOPRIENO, N., 1996. Cytogenetic monitoring of a group of Italian floriculturists: No evidence of DNA damage related to pesticide exposure. Mutation Research, 367:73-82.

SHABTAI, E.; BICHACHO, S. \& HALBRECHT, I., 1979. Cytogenetic observation in infertile men working with insecticidal compounds. Acta Geneticae Medicae et Gemellologiae, 27:51-56.

STIERUM, R. H.; HAGEMAN, G. J.; WELLE, I. J.; ALBERING, H. J.; SCHREURS, J. G. \& KLEINJANS, J. C., 1993. Evaluation of exposure reducing measures on parameters of genetic risk in a population occupationally exposed to coal fly ash. Mutation Research, 319:245-255.

SURRALLÉS, J.; CATALÁN, J.; CREUS, A.; NORPPA, H.; XAMENA, N. \& MARCOS, R., 1995. Micronuclei induced by alachlor, mitomycin $\mathrm{C}$ and vinblastine in human lymphocytes: Presence of centromeres and kinetochores and influence of staining technique. Mutagenesis, 10:417-423.

THIERENS, H.; VRAL, A. \& DE RIDDER, L., 1996. A cytogenetic study of radiological workers: Effect of 
age, smoking and radiation burden on the micronucleus frequency. Mutation Research, 360:7582.

TITENKO-HOLLAND, N.; WINDHAM, G.; KOLACHANA, P.; REINISCH, F; PARVATHAM, S.; OSORIO, A. M. \& SMITH, M. T., 1997. Genotoxicity of malathion in human lymphocytes assessed using the micronucleus assays in vitro and in vivo: A study of malathion-exposed workers. Mutation Research, 388:85-95.

TSUTSUI, T.; McLACHLAN, J. A. \& BARRET, J. C., 1983. Aneuploidy induction and cell transformation by diethylstilbestrol: A possible chromosomal mechanism in carcinogenesis. Cancer Research, 43: 3814-3821.

van BAO, R.; SZABO, I.; RUZICSKA, P. \& CZEIZEL, A., 1974. Chromosome aberrations in patients suffering acute organic phosphate insecticide intoxication. Human Genetics, 24:33-57.

van HUMMELEN, P.; GENNART, J. P.; BUCHET, J. P.; LAUWERYS, R. \& KIRSCH-VOLDERS, M., 1993. Biological markers in PAH exposed workers and controls. Mutation Research, 300:231-239.

YODER, J.; WATSON, M. \& BENSON, W. W., 1973. Lymphocyte chromosome analysis of agricultural workers during extensive occupational exposure to pesticides. Mutation Research, 21:335-340.

YUNIS, J. J., 1983. The chromosomal basis of human neoplasia. Science, 221:227-236.

Recebido em 17 de maio de 2001

Versão final reapresentada em 7 de fevereiro de 2002 Aprovado em 16 de maio de 2002 